\title{
Developing a national patient safety education framework for Australia
}

\author{
Merrilyn M Walton, Tim Shaw, Stewart Barnet, Jackie Ross
}

Qual Saf Health Care 2006;15:437-442. doi: 10.1136/qshc.2006.019216

See end of article for authors' affiliations

Correspondence to

Dr Merrilyn M Walton,

Edward Ford Building,

Faculty of Medicine,

University of Sydney,

Sydney 2006, Australia;

mwalton@med.usyd.edu.

au

Accepted 8 August 2006

Background: In 2004, The Australian Council for Safety and Quality in Health Care recognised that the lack of a comprehensive framework describing competencies for patient safety was a barrier to achieving a competent and safe health workforce. This article describes the building of a national patient safety education framework that describes the competencies for healthcare workers.

Aim: Develop an educational framework that was patient centred and identified the knowledge, skills and behaviours required by healthcare workers irrespective of their profession, position or location.

Methods: The content of the framework was developed using a four-staged approach: literature review, development of learning areas and topics, classification into learning domains and, lastly, converting into a performance-sbased format. An extensive consultation and validation process was also undertaken. Results: A national patient safety education framework was endorsed by The Australian Council for Safety and Quality in Health Care in 2005. The framework is already being used to develop curricula and train the trainer programmes in patient safety.

Conclusions: The framework, which draws its educational approach from adult learning principles, was extensively researched and built on the experience of healthcare workers. The next challenge is to test different strategies for implementing the framework.

O ver the past decade, much attention has been paid to redesigning the way health services are managed and delivered. More recently, attention has turned to preparation of the health workforce to deliver safe healthcare using knowledge and principles of patient safety. What kind of training health professionals receive in patient safety and how and where they learn remains disparate and ill defined. A review of existing health professional education curriculums and work place training shows numerous gaps, with many education and training programmes yet to incorporate patient safety elements.

In 2004, The Australian Council for Safety and Quality in Health Care $^{1}$ recognised that the lack of a comprehensive framework describing competencies for patient safety was a barrier to achieving a competent and safe workforce. This article describes the steps involved in developing a national patient safety education framework for everyone who works in the Australian healthcare system.

\section{WHAT IS THE NATIONAL PATIENT SAFETY EDUCATION FRAMEWORK (NPSEF)?}

The framework, ${ }^{1}$ published in 2005, is a simple, flexible and accessible template describing the knowledge, skills and behaviours that all healthcare workers need to ensure safe patient care. The framework is designed to assist organisations and people develop educational curriculums and training programmes, and can be accessed online at http:// www.safetyandquality.org/framework0705.pdf.

As an educational tool, the framework aims to provide a national guide to the required knowledge and performance elements needed by healthcare workers to take responsibility for patient safety. It may be used in conjunction with developing new programmes or auditing existing ones. More specifically it includes:

- What all healthcare workers should understand and know before undertaking or performing their patient safety responsibilities (their general understanding and applied knowledge)
- What all healthcare workers should be able to do when carrying out their patient safety responsibilities (performance elements comprising skills behaviours and attitudes)

- How these knowledge and performance requirements apply across four levels of responsibility in the healthcare system (from support staff to clinical and organisational leaders).

Describing patient safety requirements in terms of knowledge and performance provides a useful starting point for workplace-based training. It affords health industry organisations or training providers the opportunity to develop competency-based programmes that can contribute to an accredited or credentialled training and education system.

\section{HOW IS IT DIFFERENT FROM OTHER FRAMEWORKS AND CURRICULUMS?}

The NPSEF differs from other patient safety frameworks $\mathrm{s}^{2-5}$ and curriculums in placing the patient at the centre of care with the question "what does a health worker need to do today to keep this patient safe"? The answer to the question depends on what position a health worker holds in the organisation and his or her level of responsibility, both clinical and managerial. To date, frameworks and curriculums have been designed for particular groups of people (eg, medical specialists, nurses, allied health practitioners or students) and cover a range of fields such as adverse event reporting, minimising falls and medical errors. This framework seeks to identify all the competencies a health worker requires irrespective of his or her position or role in an organisation.

\section{Developing the structure of the framework}

Any development of an educational framework is guided by the author's vision of whom it is for and how they envisage it

Abbreviation: NPSEF, National Patient Safety Education Framework 


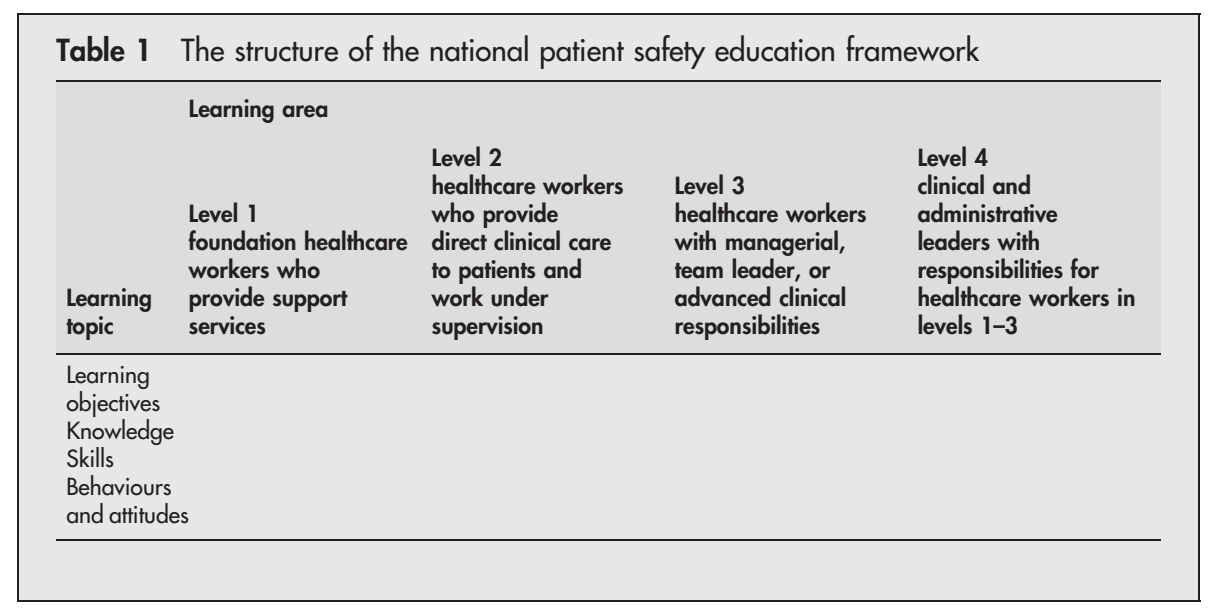

being used. The following key principles and assumptions were made about the structure of the NPSEF:

1. Applicable to all healthcare settings: The framework had to be applicable to all healthcare settings because health consumers experience healthcare in a variety of settings, not just in acute-care hospitals. ${ }^{6}$ The framework had to recognise the multiple situations and locations in which patients are treated by multiple healthcare workers.

2. Make safety everyone's business: From a patient's perspective, everyone who works in healthcare, including doctors, nurses, wards people, ambulance drivers and the hospital staff, has a responsibility to keep him or her safe. The framework therefore had to cater for the wide variety of professions and healthcare workers who make up the healthcare system. Unlike traditional frameworks, the context used to develop this one is the individual healthcare worker, irrespective of profession or occupational grouping.

3. Crosses professional boundaries: Much healthcare training and education is designed for a specific group, such as doctors, nurses, physiotherapists or psychologists. This silo approach is not appropriate in today's healthcare system, where complexity, technology and increasing specialisation are the norm. A deliberate decision was made to move away from the silo approach to training and education by identifying the learning necessary for each healthcare worker in the context of his or her clinical responsibility, relationship or association with patients, clients or carers and not with the professional or craft group to which he or she belongs.

4. Uses a patient-centred approach: The framework had to consider the current clinician-centred, disease-focused models of education and training, which inherently emphasise professional and organisational domains rather than the learning domains that put patients at the centre. This challenge was met by designing the competencies from a patient's perspective and by focusing on the outcomes and required performance for each competency developed.

5. Simple and flexible to use: Patient safety is a complex and extremely broad subject. Therefore, the framework design had to be flexible enough to cover the full range of topics and areas as well as be accessible to all healthcare workers and simple to use. Each individual healthcare worker had to be able to locate his or her required competencies on the basis of their level of responsibility for patient care.

6. Relevant to the workplace: The framework had to be relevant to the people at the coalface. It was important to recognise that many things that healthcare workers do may not be described or reflected in the literature. Therefore, the framework structure had to be sufficiently robust to allow for coalface experience to be included where appropriate. This was particularly important because of the bias in the literature towards medicine, nursing and the acute hospital.

7. Include organisational responsibilities: During early discussions with the Australian Council on Quality and Safety in Health Care, the question of the role of organisations and whether it would be possible to identify organisational patient safety competencies was raised. The framework was structured to allow for the identification of organisational competencies that focused on appropriate infrastructure and support to enable staff to develop and apply their skills and knowledge.

\section{Levels}

Through the application of the above principles, the framework describes four different levels that are based on employment role and the worker's level of clinical, managerial or support responsibility for patients and clients.

The framework starts with a foundation level of knowledge, skills and behaviours that are relevant and apply to everyone working in healthcare, irrespective of their role, rank or location. Levels 2 and 3 build on level 1 and are designed for those with more hands-on clinical, supervisory and managerial responsibilities. Level 4 stands alone and identifies organisational competencies. Table 1 shows the structure used to describe the competencies of the framework.

\section{Developing the framework}

Figure 1 summarises the methods used to develop the framework. The development of the content and framework structure is integrated with a comprehensive consultation and validation process.

\section{Content development}

The content for the framework was developed using a fourstaged approach:
1. Review of literature
2. Development of learning areas and topics
3. Classification into learning domains
4. Converting into a performance-based format

\section{Stage one: review of the literature}

A systematic review of the literature, books, reports, curriculums and web sites was undertaken to identify the 


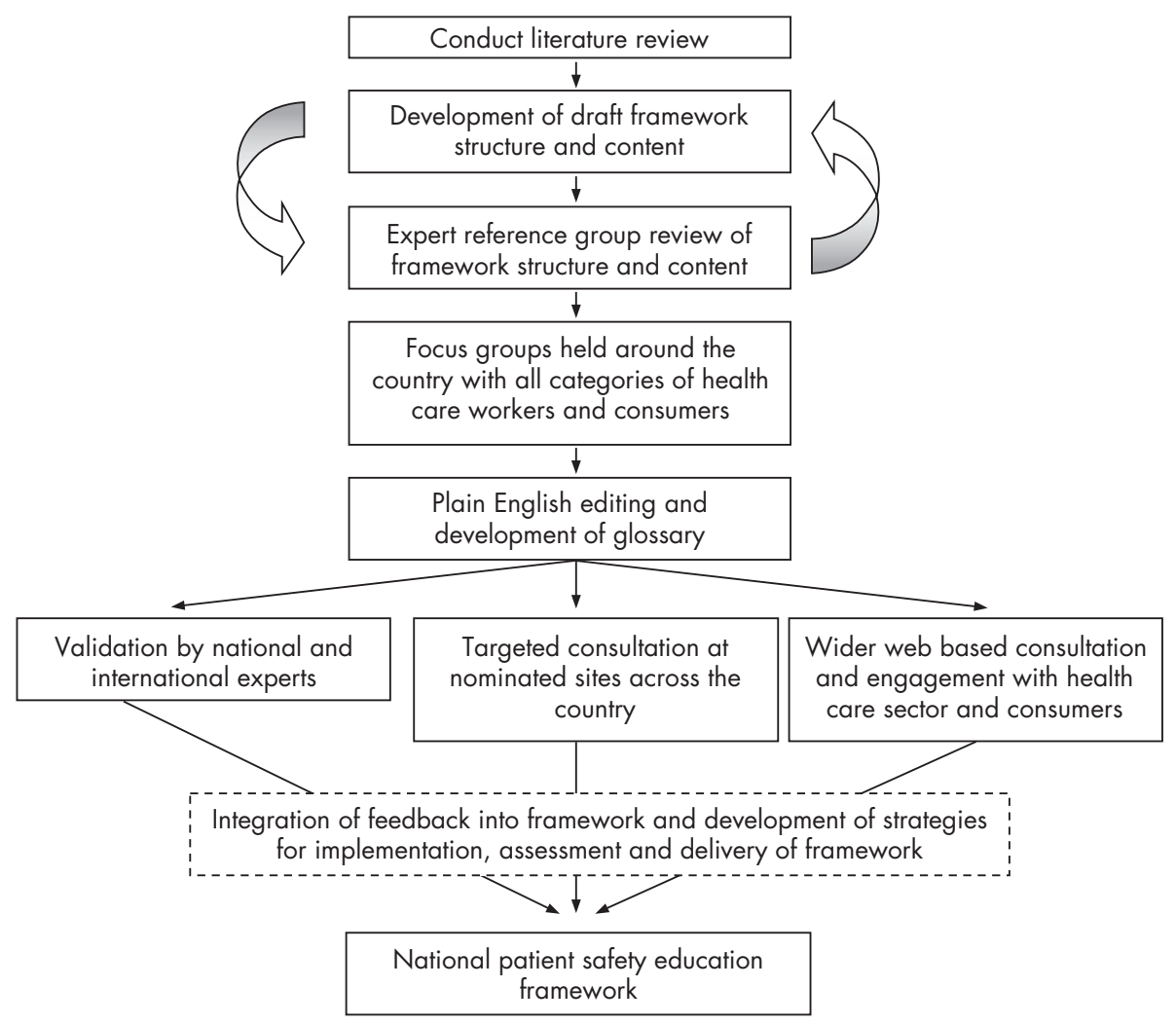

Figure 1 Schematic representation of framework development.

major practice-based activities associated with patient safety and whether the activities had a positive effect on quality and safety.

The literature on the use of frameworks to identify competencies in patient safety is under-developed, with few publications directly on the topic. Only two $\operatorname{articles}^{78}$ appeared in January 2005 under the search term "patient safety education" and three appeared under the search term "patient safety curriculum". ${ }^{49}$ The Institute of Medicine's report, Health professions education: a bridge to quality, ${ }^{2}$ identified five core competencies for health professionals, but stopped short of specifically identifying the knowledge and skills that professionals would require depending on their level of experience and responsibility.

The relevant literature relied on for identifying the competencies is mainly Level III evidence comprising descriptive studies, reports, opinions of respected authorities, protocols and standards. The literature search incorporated several categories and subcategories, including adverse events, quality improvement, mistakes, errors, communication, education and training. These key search terms were identified from major reports, books and peer-reviewed journal articles on patient safety.

The literature is biased towards the hospital workforce and delivery systems. This was adjusted in the framework, using generic descriptors to cover all possible locations and types of health service. Most evidence in the literature around safety and quality relates to health professionals. There was little reference to healthcare workers who provide support services (such as transport drivers or kitchen staff). This was compensated for in the framework by using the knowledge, skills, behaviours and attitudes for a particular professional group and creating a separate set of knowledge, skills, behaviours and attitudes that captured the essence of the activity in the context of support service areas. These domains were then validated through a consultation process.

Stage two: developing learning areas and topics All the practice-based activities identified in the literature were grouped into several learning areas. A rationale for including each learning area was written and the following seven learning areas were ultimately selected:

Seven learning areas: Adopting a patient-centred approach, each learning area was analysed for the main subject areas falling within its scope. These subject areas were named learning topics, and a rationale outlining the reason why the particular topic was important to patient safety was written for each.

Twenty two learning topics were chosen for the framework. Box 1 sets out the learning areas and topics.

The learning topics were the genesis for more extensive searching. All the practice-based activities for each topic area were listed until no more activities were forthcoming and the sources were exhausted. This list was then culled for duplication, practicality and redundancy.

Stage three: classification into learning domains This stage involved classifying each activity into a knowledge, skill or attitude/behaviour. Using the structure set out in box 1 , each list was analysed and categorised into one of the four levels of the framework.

Stage four: converting into a performance-based format The framework identifies evidence-based learning needs in terms of knowledge, skills and behaviours. These classical learning domains were coalesced into a performance-based learning guide that is better suited to workplace learning. Both these versions, classical and performance-based, are 


\section{Box 1: Learning areas and topics}

The learning areas and topics that make up this framework are as follows:

- Communicating effectively

- Involving patients and carers as partners in healthcare

- Communicating risk

- Communicating honestly with patients after an adverse event (open disclosure)

- Obtaining consent

- Being culturally respectful and knowledgeable

- Identifying, preventing and managing adverse events and near misses

- Recognising, reporting and managing adverse events and near misses

- Managing risk

- Understanding healthcare errors

- Managing complaints

- Using evidence and information

- Using best available evidence-based practice

- Using information technology to enhance safety

- Working safely

- Being a team player and showing leadership

- Understanding human factors

- Understanding complex organisations

- Providing continuity of care

- Managing fatigue and stress

- Being ethical

- Maintaining fitness to work or practice

- Ethical behaviour and practice

- Continuing learning

- Being a workplace learner

- Being a workplace teacher

- Specific issues

- Preventing wrong site, wrong procedure and wrong patient treatment

- Medicating safely

retained in the framework documentation to assist curriculum and course development. Figure 2 sets out an annotated example of the performance-based format-learning topic 1.1 involving patients and carers as partners in healthcare.

Use of patient narratives: Use of narratives in healthcare has a long tradition, but these stories are often told from the perspective of the health workers. The patients' stories are missing. Their experiences are reminders that they too are part of the healthcare team and have something to offer. A patient's story is included in each learning topic and is designed to highlight the relevance of the learning topic from his or her perspective and to bring the framework to life by giving some real examples of what can go wrong in the absence of a patient-centred approach to the delivery of healthcare services.

\section{Consultation and validation}

Figure 1 describes that a key component of the framework's development was full engagement and consultation with stakeholders and experts from across the healthcare sector and community.

Different methods were used to include as many stakeholder groups as possible in the consultation and validation process. These included:

- a national roundtable meeting

- focus groups

- workplace consultations

- web-based surveys

- national and international expert validation

\section{National roundtable}

A national roundtable was held at the beginning of the project. International health systems expert Professor Duncan Neuhasuer from Case Western Reserve University, USA, facilitated discussion with invited key stakeholders from around the country. The meeting gained endorsement for the general structure and content of the framework, identified the gaps and barriers to improving patient safety and engaged the support of key stakeholders.

The roundtable was attended by 44 people, with representatives from every state and territory, including consumers, clinicians, trainers and educators, researchers, administrators and policy officers.

\section{Focus groups}

Ten focus groups comprising health managers, healthcare workers and consumers were conducted in 2004 in Hobart, Melbourne, Adelaide, Perth, Brisbane and Sydney and was attended by over 100 people.

The focus groups:

- provided participants with information about the framework and the project;

- obtained information regarding their awareness of patient safety education programmes at the local level;

- tested the language used to describe competencies and patient safety concepts in the developing framework.

\section{Targeted consultation}

Interviews were held with healthcare workers in all categories at nine sites around the country. The sites included primary and tertiary care settings as well as both rural and metropolitan environments. Healthcare workers were interviewed using a prepared survey tool that canvassed: the workers comprehension of the performance elements; whether they currently performed these elements as part of their current duties; the perceived difficulty in performing these elements; what they believed would be the best way to learn about the performance elements in a particular learning topic; and any gaps they saw in the framework.

Over 120 healthcare workers and managers participated in this phase of the project and each individual performance element contained in the framework was covered at least four times.

\section{Wider consultation and web-based survey}

A database containing over 1500 people and organisations were compiled. Stakeholders provided feedback by email on the content and usability of the framework via the project 


\section{A guide to the framework}

Each learning topic is differentiated by colour and is presented in the framework using the following format for consisitency and ease of curriculum development. Vertical tabs alert the reader to the relevant level of the framework to facilitate navigation through the document.

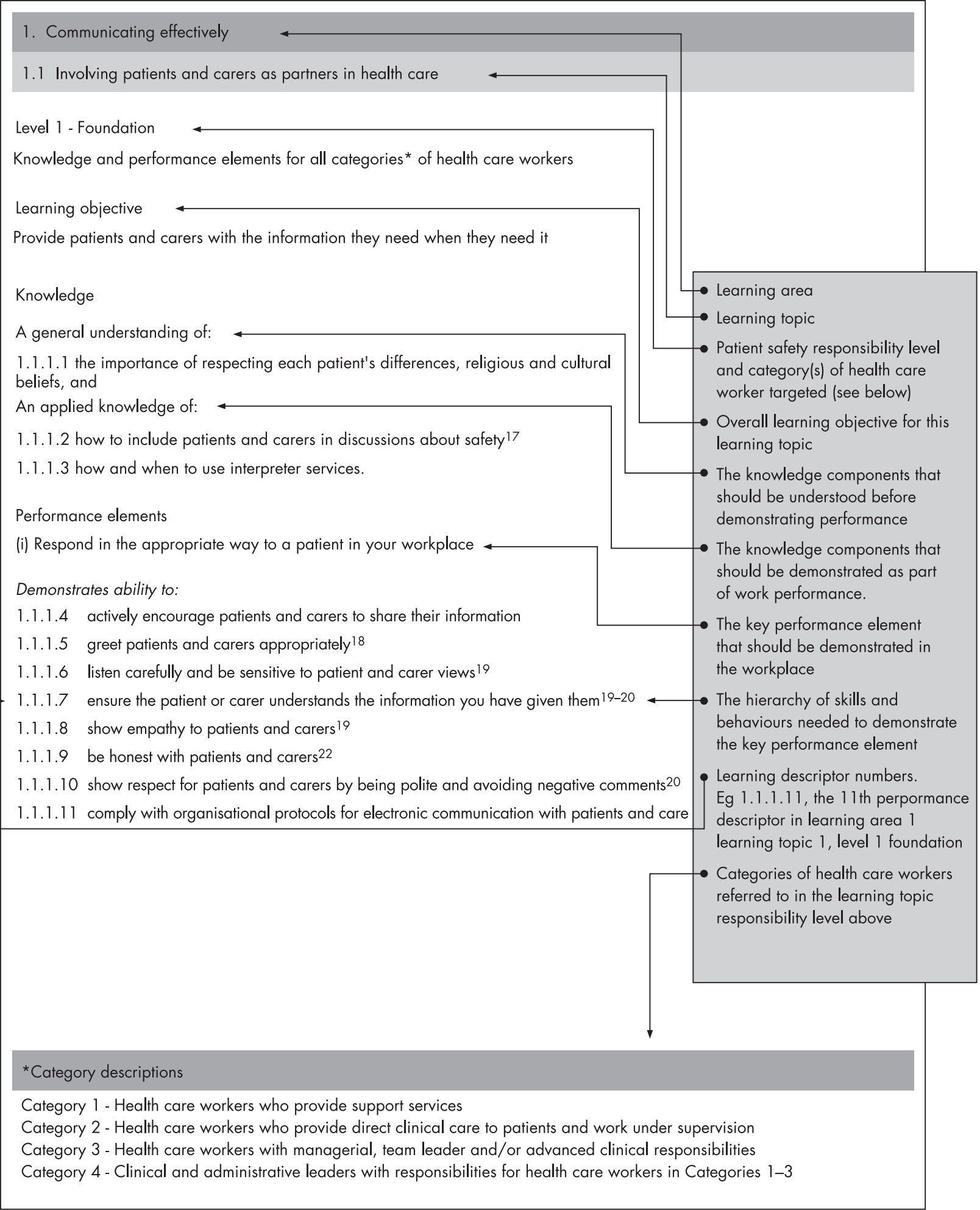

Figure 2 Performance-based format for the framework. 
website. Selected key organisations, groups and people were followed up by telephone and face-to-face interview.

\section{Expert validation}

The project expert reference group and steering committee compiled a list of national and international experts in all aspects of safety and quality. Each learning topic was sent to at least one of these experts for formal validation. For example, the learning topic on understanding human factors was sent to a US Professor of Engineering and Applied Psychology who was an acknowledged international expert in human factors. The validators are named and acknowledged in the framework.

\section{Incorporation of feedback into framework}

A formal evidence-based method was adopted to review feedback obtained during the consultation and validation process. Each stakeholder group was treated as a separate source for the collection, review and reporting of data.

Each feedback item was compared against the evidence base for the framework at a learning topic level. The development group reached a consensus before any changes were made to the framework. All stakeholder and validator feedback and actions taken were captured in a detailed report and provided to the sponsor at the completion of the project.

\section{Initial reaction to the framework}

The framework was endorsed by the Australian Council for Safety and Quality in Health Care in 2005 and has made the framework freely available.

The framework has subsequently been used in a variety of initiatives in safety and quality. These include:

- the development of undergraduate medical curriculums

- the development of vocational specialist training curriculums

- the development of train-the-trainer safety and quality packages for national implementation in the US

- the inclusion of the framework performance elements into the vocational education and training sector training package for support staff

- the use of the framework by individual safety and quality officers responsible for the development of quality and safety education and training in their organisations

\section{Conclusion}

The framework has been extensively researched and built on the experience of healthcare workers who were consulted during its development. This mirrors the quality and safety principles of the collaboration, which is evidenced based where possible and is cognisant of the voices of patients and carers

The framework draws its educational approach from the widely accepted principles of adult learning. It assumes that health workers will bring to its implementation a mature learner's view of life and learning. Although there may be performance elements in the framework's learning topics that will be new to many healthcare workers, the project's broad consultation process has shown that much of what needs to be formally learnt and assessed relates closely to existing work and life experiences.

The uptake of the framework both in Australia and overseas shows that the framework provides a valuable resource in developing initiatives in safety and quality. The real challenge for the sector is how to widely implement the framework, and this will require commitment not only from healthcare workers but also from healthcare leaders, organisations and the government.

\section{Authors' affiliations \\ M M Walton, Edward Ford Building, Faculty of Medicine, University of Sydney, Sydney, Australia \\ T Shaw, S Barnet, J Ross, Faculty of Medicine, University of Sydney, Sydney, Australia}

Competing interests: None declared.

\section{REFERENCES}

1 Australian Council on Safety and Quality in Health Care. National patient safety education framework. Canberra: Commonwealth of Australia 2005, 2005.

2 Institute of Medicine. Health professions education: a bridge to quality. Washington, DC: National Academies Press, 2003.

3 Halbach JL. Medical errors and patient safety: a curriculum guide for teaching medical students and family practice residents. In: College NYM, eds. 3rd ed. New York: New York Medical College, 2003.

4 Barach P. Patient safety curriculum. Acad Med 2000;75:551-2.

5 Singh R, Naughton B, Taylor JS, et al. A comprehensive collaborative patient safety residency curriculum to address the ACGME core competencies. Med Educ 2005;39:1 195-204.

6 Institute of Medicine. Crossing the quality chasm: a new health system for the 21 st century. Washington, DC: National Academy Press, 2001.

7 Buysse DJ, Barzansky B, Dinges D, et al. Sleep, fatigue, and medical training: setting an agenda for optimal learning and patient care [Congresses]. Sleep 2003;26:218-25.

8 Sokol P, Cummins DS. A needs assessment for patient safety education: focusing on the nursing perspective. Nurs Econ 2002;20:245-8.

9 Heffner JE, Ellis R, Zeno B. Safety in training and learning in the intensive care unit. Crit Care Clin 2005;21:129-48.

\section{bmjupdates+}

bmjupdates+ is a unique and free alerting service, designed to keep you up to date with the medical literature that is truly important to your practice.

bmjupdates+ will alert you to important new research and will provide you with the best new evidence concerning important advances in health care, tailored to your medical interests and time demands.

Where does the information come from?

bmjupdates+ applies an expert critical appraisal filter to over 100 top medical journals A panel of over 2000 physicians find the few 'must read' studies for each area of clinical interest

Sign up to receive your tailored email alerts, searching access and more...

www.bmjupdates.com 